\title{
Effects of Aronia polyphenols on the physico-chemical properties of whey, soy, and pea protein isolate dispersions
}

\author{
Mackenzie M. Hansen ${ }^{1,2^{*}}$ (D), Richard W. Hartel ${ }^{2}$ and Yrjö H. Roos ${ }^{1}$
}

\begin{abstract}
Bioactive compounds including polyphenols (PP) have been observed to naturally form non-covalent complexation interactions with proteins under mild $\mathrm{pH}$ and temperature conditions, affecting protein structures and functionality. Previously, addition of Aronia berry PP to liquid dispersions containing whey protein isolate (WPI) and sucrose was found to alter characteristics including viscosity, surface tension, and particle sizes, with changes being attributed to protein-PP interactions. In this study we aimed to investigate whether Aronia PP would interact with soy and pea protein isolates (SPI and PPI, respectively) to a similar extent as with WPI in liquid protein-sucrose-PP mixtures. We hypothesized that formulations containing PPI (comprised of larger proteins) and hydrolyzed SPI (containing more carboxyl groups) may exhibit increased viscosities and decreased aggregate sizes due to enhanced protein-PP interactions. Concentrated liquid dispersions of varied ratios of protein to sucrose contents, containing different protein isolates (WPI, SPI, and PPI), and varied Aronia PP concentrations were formulated, and physical properties were evaluated to elucidate the effects of PP addition. PP addition altered physical characteristics differently depending on the protein isolate used, with changes attributed to protein-PP interactions. SPI and PPI appeared to have higher propensities for PP interactions and exhibited more extensive shifts in physical properties than WPI formulations. These findings may be useful for practical applications such as formulating products containing fruit and proteins to obtain desirable sensory attributes.
\end{abstract}

Keywords: Whey protein, Soy protein, Pea protein, Polyphenols, Concentrated dispersions, Physico-chemical properties

\section{Introduction}

As consumers' interest towards bioactives-containing health foods grows, so does the demand for novel products with high protein contents and fruit components. Bioactives can be defined as natural compounds that may affect human health (González 2020). Globular bovine whey proteins, especially whey protein isolate (WPI) with its wide range of functionality, continue to be favored for developing products with high nutritional

\footnotetext{
* Correspondence: 116220787@umail.ucc.ie

${ }^{1}$ Food Technology, School of Food and Nutritional Sciences, University College Cork, Cork, Ireland

${ }^{2}$ Department of Food Science, College of Agricultural and Life Sciences, University of Wisconsin, Office A11, Babcock Hall, 1605 Linden Drive, Madison, WI 53706, USA
}

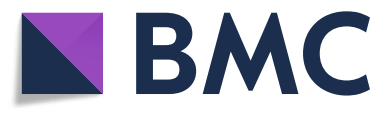

(อ The Author(s). 2021 Open Access This article is licensed under a Creative Commons Attribution 4.0 International License, which permits use, sharing, adaptation, distribution and reproduction in any medium or format, as long as you give

appropriate credit to the original author(s) and the source, provide a link to the Creative Commons licence, and indicate if changes were made. The images or other third party material in this article are included in the article's Creative Commons licence, unless indicated otherwise in a credit line to the material. If material is not included in the article's Creative Commons licence and your intended use is not permitted by statutory regulation or exceeds the permitted use, you will need to obtain permission directly from the copyright holder. To view a copy of this licence, visit http://creativecommons.org/licenses/by/4.0/.
Hansen et al. 2021a). However, consumers are also demonstrating increased interest in shifting their diets away from animal-sourced proteins for health, social, and environmental reasons, placing higher demand on plantbased nutritional options (Aschemann-Witzel \& Peschel 2019). Soybeans are a rich alternative source of highquality but inexpensive globular proteins, and soy protein isolates (SPI) are increasingly popular for product development (Li 2005). Also globular in nature, pea protein isolates (PPI) provide another alternative in formulated food products. As constituent protein sources are changed, the functional properties of the resulting food products will also be altered due to variations in the 
composition and physicochemical properties of the different protein sources.

Fruits are a rich source of polyphenols (PP), bioactive compounds with strong antioxidant and antiinflammatory activities linked to a host of positive health outcomes (Mink et al. 2007; Li et al. 2017). Good sources of PP like fresh produce often have short shelf lives, and PP are known to be chemically unstable in storage and highly susceptible to degradation (Zhao et al. 2019; Cao et al. 2021). A propensity for complexation exists between PP and proteins, with weak, noncovalent van der Waal's interactions, hydrogen bonding, and hydrophobic interactions commonly occurring in foods with neutral and acidic $\mathrm{pH}$ (Schneider, 2016). Complexation of PP with proteins has been reported to significantly change protein structures at room temperature (Rawel et al. 2005), and may potentially aid in the protection and delivery of bioactives (Cao \& Xiong 2017; Ma \& Zhao 2019; Quan et al. 2019). Additionally, plant-based protein sources including SPI and PPI tend to retain low levels of lipids that can oxidize over time, and complexation with PP may help mitigate negative effects due to their antioxidant activity.

Water hydration capacity (WHC) is a measurement of a protein powder's absorption and retention of water and is indicative of its functionality as an ingredient (Quinn \& Paton 1979). WHC is influenced by the surface properties of proteins interacting with water, the charges on protein molecules, functional groups exposed, molecular flexibility, molecular masst, and amino acid composition, and values may vary depending on how it is measured (Kneifel et al. 1991; Zayas, 1997). Proteins interact with water via hydrogen bonds with polar, hydroxyl, and carboxyl groups, electrostatic interactions with charged amino acid side chains, and hydrophobic interactions via nonpolar, hydrophobic groups exposed at the surface (Morr 1990). Proteins interact non-covalently with polyphenols at many of the same sites (Kanakis et al. 2011; Bohin et al. 2012; Le Bourvellec \& Renard 2012; Chung et al. 2015; Oancea et al., 2017). WHC is used to describe protein isolate interactions with water, but it may also serve as an indicator for the likelihood of protein-PP interactions.

While the consequences of non-covalent protein-PP interactions are not as extensively reported as those of covalent interactions (Cao \& Xiong 2017; Xue et al. 2020), liquid formulations containing WPI, sucrose, and Aronia berry extract (a rich source of PP) were found to exhibit measurable changes in physicochemical properties, attributed to non-covalent complexation interactions formed between PP and proteins (Hansen et al. 2021a). The aim of this study is to investigate whether Aronia PP interact with plant-based SPI and PPI to a similar extent as with WPI in liquid protein-
sucrose-PP mixtures, as demonstrated in our previous work. Given that WPI is known to have low WHC (Kneifel et al. 1991; Resch \& Daubert, 2002) and was still found to interact with Aronia PP, we expect that protein sources with different structures, such as SPI \& PPI, would have different WHC and propensities for interactions with Aronia PP. Varying extents of proteinPP interactions would likely result in measurable changes in physicochemical properties of the dispersions. We hypothesize that PPI formulations comprised of proteins with larger molecular masses (average for WPI $\sim 17 \mathrm{kDa}$, PPI $\sim 260 \mathrm{kDa}$ ) may exhibit enhanced viscosities, and aggregate sizes may be reduced with enhanced PP interactions (Lam et al. 2018; Ma \& Zhao 2019). It would be expected that the hydrolyzed SPI, though typically imparting reduced viscosity due to smaller protein fractions $(<35 \mathrm{kDa})$, would interact with PP more extensively due to the presence of more carboxyl groups for potential hydrogen bonding and electrostatic interactions, allowing for increased water holding, enhanced viscosities, and reduced particle sizes (Li et al. 2021). In earlier work, we presented a continuous process to form dry beads from concentrated dispersions of WPI and sucrose, with the goal of utilizing these structures for bioactives encapsulation in subsequent experiments (Hansen et al. 2020). In later studies, we developed a modified process for dry bead formation from concentrated dispersions containing Aronia PP (Hansen et al. 2021b). Preparation methods for the concentrated feed dispersions remain virtually unchanged, and this work investigates the interactions occurring in dispersions and the changes in physical behaviors of the feeds that would be prepared for subsequent dry bead formation. This work would build on the findings from previous experiments, providing insight into the non-covalent interactions between plant-based proteins and polyphenols and their effects on the physico-chemical properties of dispersions. This information may be used practically for further applications such as stabilization and delivery of actives, as well as inform the formulation and processing steps in the development of foods containing mixtures of proteins and fruit such as sports drinks, nutritional bars, smoothies, and yogurt, as well as puddings and frozen desserts in order to obtain desirable sensory properties.

\section{Materials and methods Materials}

WPI (IsoChill 9000), was supplied by Agropur, Inc. (Luxemburg, WI, USA) containing 4.6\% water, 91.6\% protein (dry basis), $0.7 \%$ fat, and $3.1 \%$ ash. SPI (ProFam $^{\circ}$ 781, hydrolyzed), was supplied by Archer Daniels Midland Co. (Decatur, IL, USA) containing 3.7\% water, $94.7 \%$ protein (dry basis), $0.4 \%$ fat, and $1.2 \%$ 
ash. PPI (VITESSENCE ${ }^{\text {ma }}$ Pulse 1803), was supplied by Ingredion $^{\text {Ts }}$ (Westchester, IL, USA) containing 8\% water, $80 \%$ protein (dry basis), $7.8 \%$ fat, and $4.2 \%$ ash. Sucrose (pure cane, extra fine, granulated sugar) was supplied by Domino Foods, Inc. (Yonkers, NY, USA). Standardized Aronia berry (Chokeberry) powder, containing a minimum of $15 \%$ anthocyanins, $10 \%$ proanthocyanidins, and $55.6 \%$ total PP, was supplied by Artemis International (Fort Wayne, IN, USA) and stored in the dark at $-18^{\circ} \mathrm{C}$. A similar extract examined in other studies was found to have high quantities of cyanidin-3-galactoside and cyanidin-3glucoside anthocyanins, as well as high levels of chlorogenic acid (Xie et al., 2016, 2017; Hansen et al., 2021a). Technical data sheets for the extract reported $<5 \%$ water content, $2.13 \%$ protein, $1.3 \%$ fiber, $0.85 \%$ sugars, $0.29 \%$ fat, and a reconstituted $\mathrm{pH}$ of 3-4. Deionized (D.I.) water was used throughout all experiments.

\section{Protein isolate powders characterization Water hydration capacity}

WPI, SPI, and PPI powders were evaluated for their respective WHC by modifying the two-step method presented by Quinn and Paton (1979). The first step, used to obtain an approximate $\mathrm{WHC}$ for each protein isolate, was performed in triplicate. The test involved the gradual wetting of $5 \mathrm{~g}$ of protein powder with unmeasured amounts of deionized (D.I.) water in $50 \mathrm{~mL}$ centrifuge tubes, mixing vigorously with a spatula until the samples were thoroughly wetted and mixtures had paste-like consistencies. Tubes were placed in a Sorvall ${ }^{\circ}$ RC 26 Plus centrifuge (Sorvall Products, L.P., Newtown, CT, USA $)$ and spun at $5100 \mathrm{rpm}(\sim 2000 \mathrm{x} \mathrm{g})$ for $10 \mathrm{~min}$ at $20-25{ }^{\circ} \mathrm{C}$. The small quantities of supernatant formed were decanted and tubes were weighed to determine the masses of water absorbed by the powders. Triplicate data were averaged and crude WHC values obtained were used to determine water addition levels for step 2. A minimum of 5 tubes containing $5 \mathrm{~g}$ of protein powder were prepared as described for step 1, but with a range of known water contents in $1 \mathrm{~g}$ increments, both above and below the approximate WHC. After centrifugation under the same conditions, tubes were evaluated to determine the water addition level at which a supernatant was formed, giving more exact WHC values within $1 \mathrm{~g}$.

\section{Dispersion preparation}

Dispersions were prepared as described in previous work (Hansen et al. 2021a), where dry protein-sucrose blends were dispersed in D.I. water, then aliquots of Aronia extract solution were added to form the final mixtures at room temperature. $\mathrm{pH}$ was measured with a FiveEasy Plus $\mathrm{pH} / \mathrm{mV}$ meter with InLab ${ }^{\bullet}$ Viscous Pro-ISM probe
(Mettler Toledo, Hampton, Schwerzenbach, Switzerland) after calibrating the electrode at $\mathrm{pH}$ four and seven at room temperature, $<25^{\circ} \mathrm{C}$.

Twenty-seven formulations of varied compositions were prepared in triplicate for subsequent, randomized triplicate analysis in a $3 \times 3 \times 4$ factorial design (Table 1); the 9 remaining WPI-based formulations were prepared and analyzed previously, and the data were used for comparison (Hansen et al. 2021a). Protein to sucrose ratios and total solids contents of dispersions were selected based on findings from previous work (Hansen et al. 2020, 2021a). We aimed to compare dispersions without the active $(0 \%)$ to formulations with three different concentrations of PP, selecting concentrations to build upon the findings from previous studies (Hansen et al. 2021a). Dispersions defoamed at room temperature for a minimum of $1 \mathrm{~h}$ before analyses.

\section{Feed characterization Flow testing}

Flow properties of dispersions including the time required to deposit $10 \mathrm{~mL}$ of dispersion, the number of drops deposited per $1 \mathrm{~min}$, the mass of $10 \mathrm{~mL}$ of dispersion, and individual drop masses were measured at room temperature, as detailed in previous work (Hansen et al. 2020, 2021b), while pumping dispersions at a constant rate through a benchtop peristaltic pump (120 S/DV, Watson Marlow, Falmouth, England; silicon tubing $85 \mathrm{~cm}$ length, $2 \mathrm{~mm}$ bore, $1 \mathrm{~mm}$ wall, BÜCHI Labortechnik AG, Flawil, Switzerland). Those measurements provided the data necessary to calculate mass and volume flow rates, dispersion densities, drop surface tensions, drop diameters, and drop volumes (Hansen et al. 2020, 2021a).

\section{Viscosity}

Utilizing methods reported in previous work (Hansen et al. 2021a), where $1 \%$ strain was determined to be within the LVR of dispersions measured, a DHR-2 rheometer (TA Instruments, DE, USA) was used to measure the rheological properties of dispersions at $25^{\circ} \mathrm{C}$ in triplicate with small-strain oscillatory measurements; complex viscosity values were recorded.

\section{Particle size distribution}

Using the methods explained in Hansen et al. (2021a), particle size distributions of dispersions were measured with a Malvern Mastersizer 2000 (Malvern Instruments Ltd., Worcestershire, U.K.) in triplicate, by injecting drops of dispersions at room temperature into a Hydro $2000 S$ liquid sampler with D.I. water as the dispersant until dilutions reached obscurations between 11 and $15 \%$ (WPI refractive index 1.545, D.I. water refractive index 1.33, absorbance 0.001). 
Table 1 Formulations

\begin{tabular}{|c|c|c|c|c|c|c|}
\hline Protein:sucrose & Protein isolate & [PP] & $\mathrm{pH}$ & Density & Diameter (calculated) & Diameter (frozen) \\
\hline- & - & $\% \mathrm{w} / \mathrm{w}$ & - & $\mathrm{kg} / \mathrm{m}^{3}$ & $\mathrm{~mm}$ & $\mathrm{~mm}$ \\
\hline 0.75 & WPI & 0 & 6.03 & $1019 \pm 10$ & $4.59 \pm 0.02$ & $4.45 \pm 0.09$ \\
\hline 1 & WPI & 0 & 6.08 & $1019 \pm 6$ & $4.60 \pm 0.02$ & $4.58 \pm 0.10$ \\
\hline 1.25 & WPI & 0 & 6.01 & $1014 \pm 15$ & $4.54 \pm 0.03$ & $4.48 \pm 0.05$ \\
\hline 0.75 & WPI & 0.5 & 5.73 & $1015 \pm 11$ & $4.67 \pm 0.03$ & $4.63 \pm 0.03$ \\
\hline 1 & WPI & 0.5 & 5.94 & $994 \pm 25$ & $4.67 \pm 0.04$ & $4.63 \pm 0.09$ \\
\hline 1.25 & WPI & 0.5 & 5.95 & $993 \pm 28$ & $4.65 \pm 0.06$ & $4.55 \pm 0.14$ \\
\hline 0.75 & WPI & 1 & 5.57 & $994 \pm 15$ & $4.65 \pm 0.08^{*}$ & $4.39 \pm 0.08^{\mathrm{a}}$ \\
\hline 1 & WPI & 1 & 5.72 & $1021 \pm 10$ & $4.70 \pm 0.03$ & $4.50 \pm 0.12$ \\
\hline 1.25 & WPI & 1 & 5.84 & $1020 \pm 8$ & $4.67 \pm 0.05$ & $4.65 \pm 0.02$ \\
\hline 0.75 & WPI & 1.5 & 5.29 & $1026 \pm 30$ & $4.67 \pm 0.06$ & $4.57 \pm 0.15$ \\
\hline 1 & WPI & 1.5 & 5.36 & $1012 \pm 7$ & $4.69 \pm 0.01^{\mathrm{a}}$ & $4.47 \pm 0.09^{a}$ \\
\hline 1.25 & WPI & 1.5 & 5.41 & $1006 \pm 12$ & $4.64 \pm 0.07^{a}$ & $4.53 \pm 0.12^{\mathrm{a}}$ \\
\hline 0.75 & SPI & 0 & 6.56 & $1041 \pm 13$ & $4.52 \pm 0.02^{\mathrm{a}}$ & $4.45 \pm 0.07^{\mathrm{a}}$ \\
\hline 1 & SPI & 0 & 6.52 & $1051 \pm 9$ & $4.41 \pm 0.05^{a}$ & $4.50 \pm 0.09^{a}$ \\
\hline 1.25 & SPI & 0 & 6.55 & $1037 \pm 14$ & $4.50 \pm 0.02$ & $4.52 \pm 0.14$ \\
\hline 0.75 & SPI & 0.5 & 6.30 & $1021 \pm 13$ & $4.51 \pm 0.07$ & $4.49 \pm 0.07$ \\
\hline 1 & SPI & 0.5 & 6.32 & $1032 \pm 11$ & $4.47 \pm 0.04^{\mathrm{a}}$ & $4.39 \pm 0.09^{a}$ \\
\hline 1.25 & SPI & 0.5 & 6.35 & $1021 \pm 11$ & $4.50 \pm 0.03$ & $4.51 \pm 0.12$ \\
\hline 0.75 & SPI & 1 & 6.03 & $1022 \pm 11$ & $4.54 \pm 0.03$ & $4.57 \pm 0.11$ \\
\hline 1 & SPI & 1 & 6.09 & $1016 \pm 14$ & $4.53 \pm 0.03^{\mathrm{a}}$ & $4.41 \pm 0.13^{\mathrm{a}}$ \\
\hline 1.25 & SPI & 1 & 6.21 & $1021 \pm 21$ & $4.49 \pm 0.06$ & $4.50 \pm 0.14$ \\
\hline 0.75 & SPI & 1.5 & 5.84 & $844 \pm 164$ & $4.86 \pm 0.34^{a}$ & $4.54 \pm 0.08^{a}$ \\
\hline 1 & SPI & 1.5 & 5.98 & $956 \pm 92$ & $4.63 \pm 0.14$ & $4.55 \pm 0.13$ \\
\hline 1.25 & SPI & 1.5 & 5.98 & $788 \pm 94$ & $4.79 \pm 0.23^{a}$ & $4.39 \pm 0.18^{a}$ \\
\hline 0.75 & PPI & 0 & 6.85 & $1043 \pm 20$ & $4.39 \pm 0.10$ & $4.31 \pm 0.07$ \\
\hline 1 & PPI & 0 & 6.75 & $1042 \pm 21$ & $4.21 \pm 0.03^{a}$ & $4.53 \pm 0.15^{a}$ \\
\hline 1.25 & PPI & 0 & 6.96 & $976 \pm 24$ & $4.29 \pm 0.07^{a}$ & $4.58 \pm 0.17^{a}$ \\
\hline 0.75 & PPI & 0.5 & 6.67 & $1037 \pm 15$ & $4.51 \pm 0.10^{a}$ & $4.75 \pm 0.15^{a}$ \\
\hline 1 & PPI & 0.5 & 6.46 & $1039 \pm 15$ & $4.31 \pm 0.05^{a}$ & $4.57 \pm 0.19^{a}$ \\
\hline 1.25 & PPI & 0.5 & 6.58 & $1019 \pm 32$ & $4.20 \pm 0.09^{a}$ & $4.67 \pm 0.14^{a}$ \\
\hline 0.75 & PPI & 1 & 6.15 & $1021 \pm 27$ & $4.67 \pm 0.05^{a}$ & $4.81 \pm 0.16^{a}$ \\
\hline 1 & PPI & 1 & 6.22 & $1025 \pm 35$ & $4.60 \pm 0.08$ & $4.68 \pm 0.22$ \\
\hline 1.25 & PPI & 1 & 6.42 & $1020 \pm 15$ & $4.46 \pm 0.05^{a}$ & $4.71 \pm 0.26^{a}$ \\
\hline 0.75 & PPI & 1.5 & 5.82 & $1027 \pm 20$ & $4.65 \pm 0.04$ & $4.64 \pm 0.21$ \\
\hline 1 & PPI & 1.5 & 6.03 & $1029 \pm 18$ & $4.62 \pm 0.04^{\mathrm{a}}$ & $4.92 \pm 0.23^{\mathrm{a}}$ \\
\hline 1.25 & PPI & 1.5 & 6.26 & $1028 \pm 15$ & $4.54 \pm 0.02$ & $4.72 \pm 0.27$ \\
\hline
\end{tabular}

*values with superscript letters showed significant differences between calculated and measured diameters

values in italics were from previous work (Hansen et al., 2021a; averaged data reported, $n=6,3$ for frozen diameters)

Density and estimated drop diameters measured and calculated from flow tests data and measured diameters ( $\mathrm{mm}$ ) of frozen drops (averaged data reported, $n=$ 9) formed from feed dispersions with varied protein:sucrose, protein isolates, polyphenols (PP) concentrations, and $\mathrm{pH}$

\section{Optical light microscopy}

Protein particles and protein-PP complexes in diluted dispersions at room temperature were observed with a Nikon Eclipse FN1 optical microscope
(Nikon Instruments Inc., Melville, NY, USA) and a Nikon Digital Sight DS-U3 camera control unit attached (ver. 1), as reported in previous work (Hansen et al. 2021a). 


\section{Centrifuge separation}

Slightly modifying sample preparation methods from previous studies (Hansen et al. 2021a), $1.25 \mathrm{~g}$ aliquots of 5 -times diluted dispersions were pipetted into tubes (1.5 $\mathrm{mL}$ graduated tubes with flat caps, Fisherbrand ${ }^{\circ}$ Fisher Scientific, Hampton, NH, USA) and centrifuged at $12,000 \mathrm{rpm}(\sim 13,523 \mathrm{x} \mathrm{g})$ and $20^{\circ} \mathrm{C}$ for $20 \mathrm{~min}$ in a microcentrifuge (Centrifuge 5424 $\mathrm{R}$ with FA-45-24-11 rotor, Eppendorf, Hamburg, Germany). Tubes were observed after centrifugation.

\section{Frozen drop preparation}

Beads were frozen solid as described in previous work (Hansen et al. 2021a), by dropping dispersions into liquid nitrogen $\left(\mathrm{LN}_{2}\right)$ (100\% purity; Airgas, Madison, WI, USA). Drops were allowed to solidify for $\sim 5 \mathrm{~min}$ prior to removal from the $\mathrm{LN}_{2}$ and immediate diameter measurements.

\section{Frozen drop diameters}

As in previous work, digital Vernier calipers $(0-150 \mathrm{~mm}$; Stainless Hard) were used to measure the diameters of frozen beads (Hansen et al. 2021a). Measurements were performed in triplicate for each formulation replicate $(n=9)$.

\section{Statistical analysis}

Experiments were performed three times and analyzed in triplicate $(n=9)$; mean values and standard deviations were calculated from the data collected. To compare mean values, analysis of variance (3-way ANOVA; Tukey's HSD test) and independent measures t-tests (equal variance not assumed) were performed using JMP Pro version 15.0.0 (SAS Institute Inc., Cary, NC, USA). The level of significance was determined at $p<$ 0.05 .

\section{Results and discussion \\ Protein isolate powders characterization Water hydration capacity}

WHC is indicative of a protein powder's functionality as an ingredient. WHC values for WPI, SPI (hydrolyzed), and PPI powders are reported in Table 2. As reported in previous studies, WPI solubilized well in D.I. water and

Table 2 Water hydration capacity

\begin{tabular}{ll}
\hline Protein isolate & Water hydration capacity \\
\hline- & ( $\mathrm{g}$ water absorbed per g powder) \\
Whey & 0 \\
Soy (hydrolysate) & 1.4 \\
Pea & 2.9
\end{tabular}

Water hydration capacity of WPI, SPI (hydrolyzed), and PPI powders, reported as grams of water absorbed per gram of protein isolate powder after centrifugation a single, viscous phase remained, giving a WHC value of $0 \mathrm{~g}$ of water absorbed per gram of WPI (Kneifel et al. 1991; Resch \& Daubert 2002). Five grams of SPI absorbed between 6.5 and $7.5 \mathrm{~g}$ of water $(\sim$ $1.4 \mathrm{~g} / \mathrm{g}$ ), and five grams of PPI absorbed between 14.1 and $15.1 \mathrm{~g}$ of water $(\sim 2.9 \mathrm{~g} / \mathrm{g})$, in agreement with the ranges of capacities reported by Owusu-Ansah and McCurdy (1991) and Zayas (1997). Fleming et al. (1974) reported higher water absorption values for commercial SPI powders, ranging from $4.15-7.75 \mathrm{~g}$ water absorbed per $\mathrm{g}$ SPI; it is possible that the commercial powders studied underwent greater extents of hydrolysis than ours, resulting in higher quantities of carboxyl groups present for interactions with water. Sosulski and McCurdy (1987) reported water holding capacity values of 2.65 and $2.52 \mathrm{~g}$ of water per gram of SPI and PPI at $21^{\circ} \mathrm{C}$, respectively. Swanson (1990) reported that at neutral $\mathrm{pH}$, SPI retained 4-5 times its initial weight of water, and 2.7-2.8 times its weight for PPI. Fuhrmeister and Meuser (2003) reported WHC values of $4.6 \mathrm{~g}$ water per $\mathrm{g}$ commercial SPI, and $4 \mathrm{~g}$ water per $\mathrm{g}$ commercial PPI. It is likely that the isolates used in this study have different properties from those used in other work, thus resulting in differing WHC data.

As there is substantial overlap between the locations where proteins can interact with water and interact noncovalently with PP (Morr 1990; Kanakis et al. 2011; Bohin et al. 2012; Le Bourvellec \& Renard 2012; Chung et al. 2015; Oancea et al. 2017), WHC, typically used to describe interactions with water, might also be able to describe the potential for protein-PP interactions. Given that WPI had the lowest WHC of the proteins studied, it is possible that WPI would have the least interactions with PP. SPI and PPI, with higher WHC values imparted by their differing structures with more sites available for interactions, may interact more extensively with the Aronia PP and yield greater measurable changes in physicochemical properties than WPI formulations.

\section{Feed characterization \\ $p H$}

As reported in earlier work (Hansen et al. 2021a), pH of the dispersions was observed to decrease slightly with increasing PP concentration (Table 1). Variations in $\mathrm{pH}$ may influence the structure of proteins in solution, determining which side groups are exposed and how many bindings sites may be available for intermolecular interactions and binding (Rawel et al. 2005), as well as affect functional properties of dispersions including viscosity and particle size (Spencer et al. 1988; Saluja \& Kalonia 2005; Cao \& Xiong 2017; Hong et al. 2018). As the pH of dispersions approaches the protein isoelectric point (pI), proteins are more likely to undergo intermolecular 
interactions and aggregate, which can result in increased viscosity (Song 2009; Coupland 2014).

Use of $1.5 \%$ Aronia PP in WPI dispersions induced $\mathrm{pH}$ to near the $\mathrm{pI}$ values reported in the literature for constituent $\beta$-lactoglobulin ( $\mathrm{pI} \sim 5.2-5.3$; the major protein fraction in WPI), though values for $\alpha$-lactalbumin $(\sim 4.2-4.8)$ were not reached (Table 1) (Kilara \& Harwalkar 1996; Demetriades \& McClements 1998; Jean et al. 2006). pH of SPI dispersions was found to decrease with increasing PP concentration and approach the range of $\mathrm{pI}$ values reported for $\beta$-conglycinin, the minor $7 \mathrm{~S}$ protein fraction in SPI ( $\mathrm{pI} \sim 5.2-6.4$; Table 1$)$. The $\mathrm{pI}$ of the major $11 \mathrm{~S}$ protein fraction, glycinin ( $\mathrm{pI} \sim 4.8$ ), was not nearly reached (Petruccelli \& Añón 1995; Li 2005). $\mathrm{pH}$ values of PPI dispersions were also reduced with increased PP concentration (Table 1), but did not approach the $\mathrm{pI}$ values reported in the literature for constituent vicilin ( $\mathrm{pI} \sim 5.5$ ) or legumin ( $\mathrm{pI} \sim 4.8$ ) protein fractions (Owusu-Ansah \& McCurdy 1991; Lam et al. 2018). Assuming a range of pI for WPI, SPI, and $\mathrm{PPI}$, it is possible that the reduced $\mathrm{pH}$ values could play a minor role affecting the physical properties of these dispersions.

\section{Interfacial tension}

An individual drop will form when the gravitational forces acting on it overcome the surface tension forces around the circumference of the tubing tip, confirming surface tension as a major determinant of the sizes of drops produced (Hansen et al. 2021a). The ANOVA reported that changing the ratio of protein to sucrose had a significant effect $(p<0.05)$ on calculated surface tensions of dispersions. Tukey's HSD tests clarified further, indicating that as protein:sucrose ratios increased, surface tensions significantly decreased $(p<0.05)$, and all three ratios had significantly different surface tension values (Fig. 1a). Sucrose is not thought to appreciably affect surface tension, as sugars are not particularly surface-active; proteins are known surfactants and may adsorb to liquid-gas interfaces and decrease surface tensions (Kitabatake \& Doi 1988). In previous studies, changing the ratio of WPI to sucrose in dispersions did not meaningfully impact surface tension (Fig. 1a samples marked*; Hansen et al. 2021a); this observation was confirmed by additional data for WPI dispersions containing $1.5 \%$ PP. Similarly, altering SPI:sucrose ratios in dispersions did not notably affect surface tension. Surface tensions of PPI dispersions decreased with increasing PPI concentrations, regardless of PP concentration (Fig. 1a).

Changing the type of protein isolate in formulations between WPI, SPI, and PPI also had a significant effect $(p<0.05)$ on surface tension, according to the ANOVA. Corresponding Tukey's HSD tests indicated that WPI dispersions had the highest surface tensions, while PPI formulations had the lowest, and all three protein isolates were significantly different from each other. In ranking the surfactant abilities to reduce surface tensions of dispersions, WPI would be lowest and PPI highest; these mirror the findings for WHC, which may indicate the differing extent to which the isolates interact with water.

According to the ANOVA, changing the PP concentrations in dispersions had a significant effect on surface tension $(p<0.05)$. Tukey's HSD tests provided more detail, specifying that increasing PP concentrations resulted in significantly increased surface tensions $(p<0.05)$, and the values for all four PP concentrations were significantly different from each other (Fig. 1b). This trend was observed most clearly in dispersions formulated with
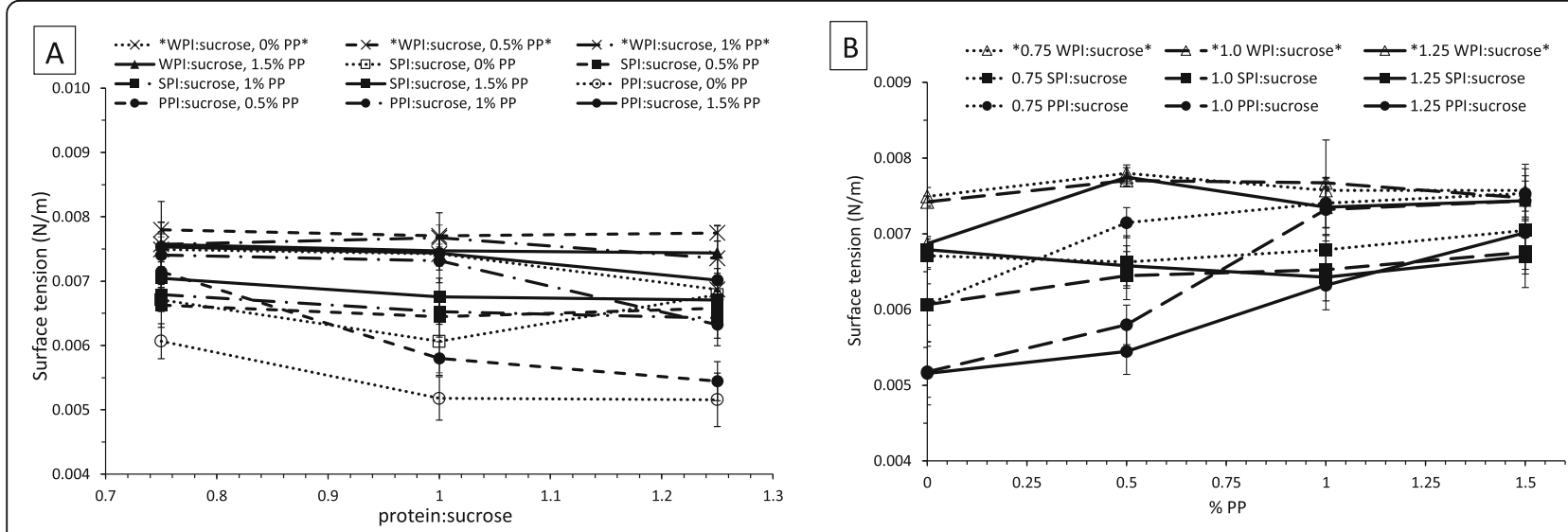

Fig. 1 Effect of protein:sucrose ratio (A) and PP content (\%) (B) on the calculated surface tension ( $\mathrm{N} / \mathrm{m})$ of dispersions at $25^{\circ} \mathrm{C}$; (averaged data plotted, $n=9$ ). Legend entries marked * contain data reported in previous work (Hansen et al., 2021a; averaged data plotted, $n=6$ ). Lines are for guiding purposes only 
PPI, while many conditions, including WPI formulations and some SPI dispersions, showed no meaningful trends. These findings build on those from earlier studies, where increasing PP concentrations in WPI-sucrose dispersions resulted in increased surface tensions under few conditions, but many conditions showed no meaningful trends (Fig. 1b samples marked* with unfilled markers; Hansen et al. 2021a). As in previous work, variations in trends observed may be attributed to air entrapped in dispersions giving altered surface tension calculations. With optimal PP and protein types and environmental conditions, protein-PP complexation interactions may be enhanced with increased PP, forming complexes that can grow into larger aggregates (Spencer et al. 1988; Charlton et al. 2002; Rawel et al. 2005; Ozdal et al. 2013). As discussed in previous studies (Hansen et al. 2021a), the increased incidence of large protein-PP aggregates in dispersions would likely generate more intermolecular interactions, and liquids containing higher quantities of strong, attractive intermolecular forces are known to have higher surface tensions ( $\mathrm{He}$ et al. 2011; Tro et al. 2014); this may explain the rising surface tensions observed with increasing PP. It is also possible that, as PP increased, the surfactant abilities of proteins in dispersions to lower surface tension were reduced as a result of enhanced protein-PP interactions occurring and occupying sites available for other interactions. This may also explain the increased surface tensions with increasing PP.
Previous studies have indicated that drop diameters and surface tensions are directly related; as surface tensions decrease, so do the diameters of the resulting drops (Chan et al. 2009). The best fit line applied upon plotting the calculated diameters of drops against the calculated surface tensions of dispersions showed a positive slope (Fig. 2), indicative of a direct correlation $\left(R^{2}=0.72\right)$, as described by Lee and Chan (2013) and observed in previous work (Hansen et al., 2021a). As discussed in earlier work, the few data points scattered from the correlation may be caused by inaccurate drop diameter and surface tension calculations based on density measurements that can vary with the inclusion of air bubbles in the proteincontaining dispersions, as well as the inherent variation within food ingredients (Hansen et al. 2021a). Corresponding density data indicates relatively consistent amounts of entrapped air in dispersions, with few formulations showing enhanced air holding abilities and thus lower measured densities, which may affect the scatter (Table 1).

As reported in earlier studies, more specific methods of surface tension measurement could potentially provide more accuracy than the drop mass method employed (Worley 1992). However, these methods would not be compatible with the dispersions in focus due to their viscosities, stickiness, turbidity, entrapped air, and dark colors when Aronia is present (Hansen et al. 2021a).

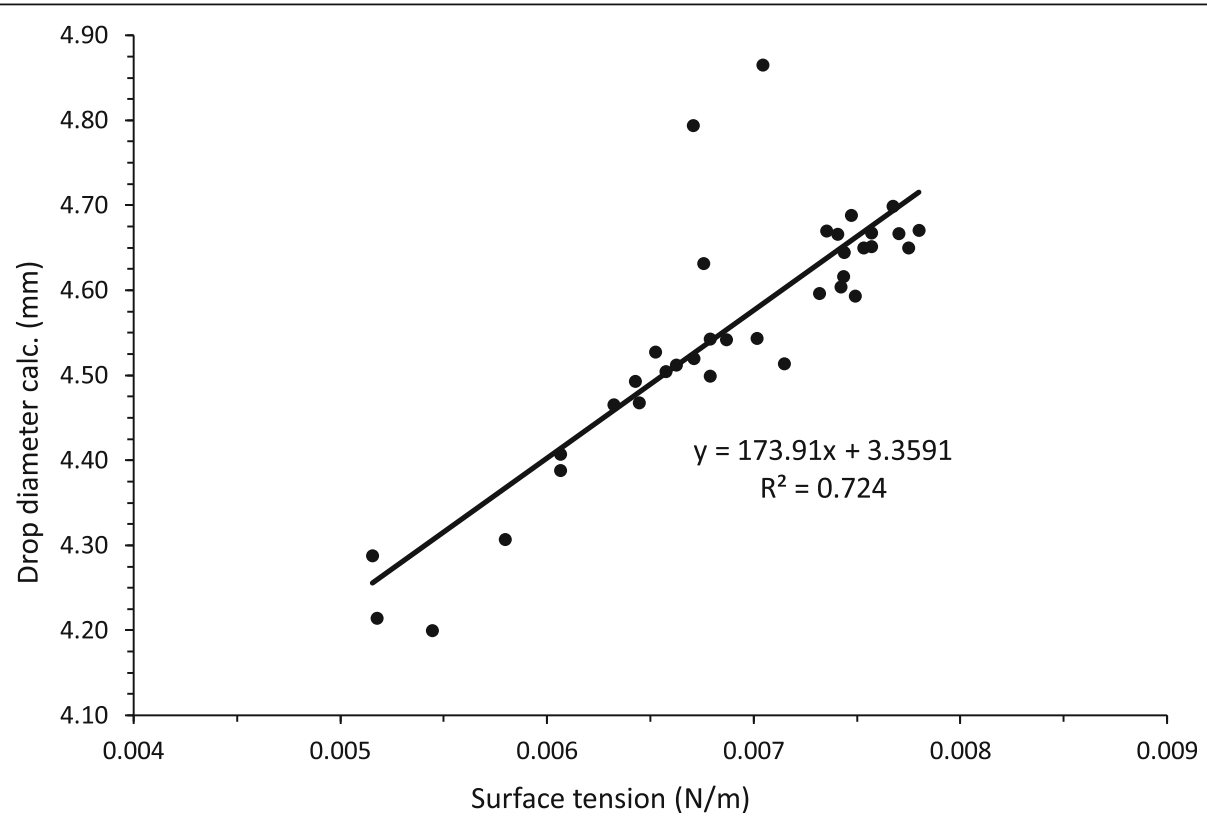

Fig. 2 The relationship between the average surface tensions $(\mathrm{N} / \mathrm{m})$ of feed dispersions containing protein:sucrose ratios of $0.75,1.0$, and 1.25, PP contents of $0,0.5,1$, and $1.5 \%$, and protein isolates including WPI, SPI, and PPI at $25^{\circ} \mathrm{C}$ and average calculated diameters (mm) of drops 


\section{Viscosity}

Viscosity is related to the fluid flow properties of dispersions and can strongly influence processing and manufacturing operations (Johnson et al. 1975; Hartel et al. 2018; Hansen et al. 2021a). According to the ANOVA, the ratio of protein to sucrose had a significant $(p<0.05)$ effect on viscosity, where increases in ratios resulted in increased viscosities. Tukey's HSD tests clarified that all ratios had significantly different viscosities from one another. These ANOVA results are only visually demonstrated in Fig. 3a for PPI formulations containing 0 and $0.5 \%$ PP and SPI dispersions with 1.5\% PP; those few formulations most strongly influenced the ANOVA results, despite the majority of formulations showing no major changes in viscosity with increasing protein:sucrose ratios. Earlier work also reported significant increases in dispersion viscosities with increasing WPI:sucrose ratios, but only when dispersions total solids contents were greater than 35\% (Hansen et al. 2021a). These results are generally in agreement with those from previous experiments, where dispersions containing $25 \%$ total solids did not show major shifts in viscosity with changing WPI:sucrose ratios, as the effect of changing protein:sucrose ratios was thought to be relatively weak compared to the effect of \% total solids. The increases in dispersion viscosities observed with increasing PPI:sucrose ratios and low PP concentrations may be due to the large molecular mass proteins at higher concentrations having increased opportunities for overlapping, intermolecular protein-protein interactions, and network formation (Song 2009; Coupland 2014); lower PPI:sucrose ratios may have a diluting effect on the protein-protein networks and thus behave more similarly to other, less viscous WPI and SPI dispersions.
Changing the protein isolate in formulations between WPI, SPI, and PPI had a significant effect $(p<$ $0.05)$ on viscosities of dispersions, according to the ANOVA. Tukey's HSD tests provided further detail, reporting that WPI dispersions had the lowest average viscosities, while PPI dispersions had the highest, and the average viscosities of dispersions containing each protein isolate were significantly different from each other. These findings generally agree with those reported by Krstonošić et al. (2020), where aqueous solutions of whey protein concentrate at varied concentrations had lower viscosities than pea and soy protein isolate solutions. In comparing the different protein isolates abilities to reduce surface tensions of dispersions, WPI was found to have the lowest efficacy and PPI the highest, mirroring the findings for the WHC of the isolates. Similarly, WPI had the lowest impact on viscosities of dispersions, indicative of adequate electrostatic repulsion between proteins, while PPI had the highest impact on viscosity, likely due to its large average molecular mass and the increased likelihood of protein-protein interactions. Additionally, PPI dispersions may have differing viscous properties due to the varied extents of hydration undergone by each protein isolate; PPI appears to have undergone a lesser extent of protein hydration prior to testing, as indicated by the presence of large insoluble PPI particles in dispersions.

According to the ANOVA, increasing PP in dispersions was found to have a significant effect $(p<0.05)$ on viscosity, where viscosities generally decreased with increasing PP until increasing at 1.5\% PP. Corresponding Tukey's HSD tests indicated that dispersions with differing PP had significantly different viscosities from one another. The decreasing viscosity relationship with
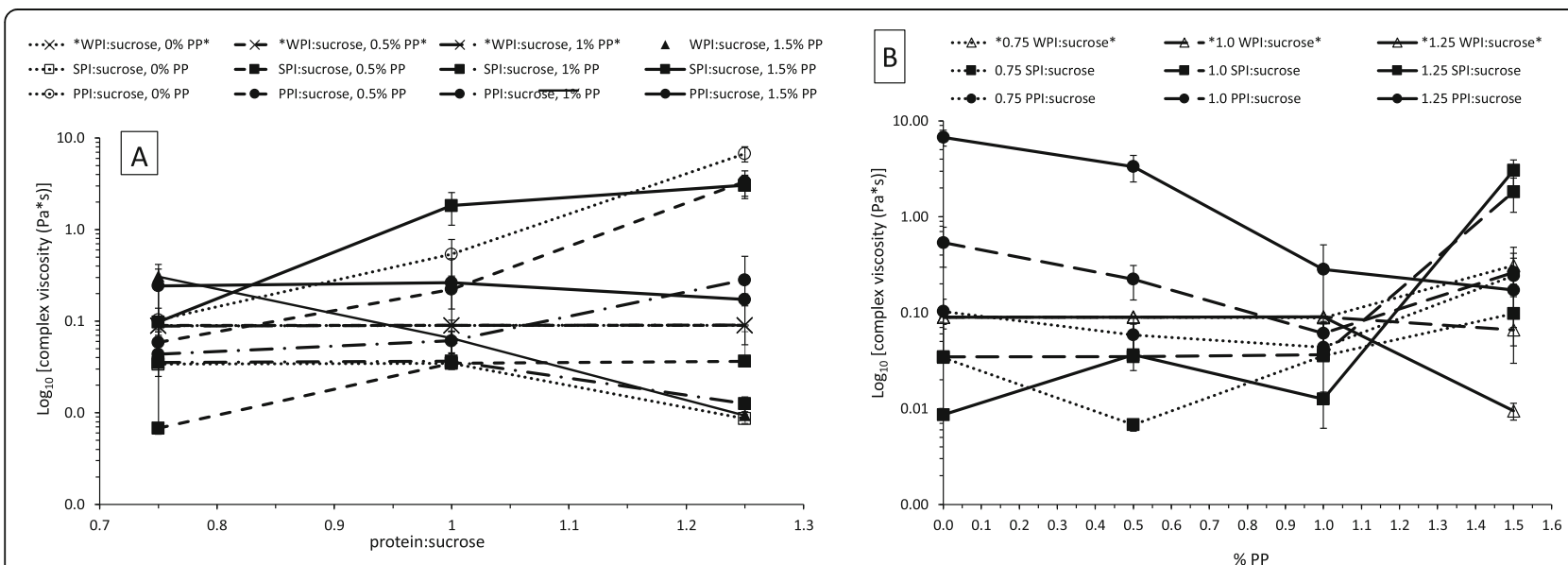

Fig. 3 Effect of protein:sucrose ratio (A) and PP content (\%) (B) on the complex viscosity ( $\left.\mathrm{Pa}{ }^{*} \mathrm{~s}\right)$ of dispersions at $25^{\circ} \mathrm{C}$; (averaged data plotted, $n=9$ ). Legend entries marked ${ }^{*}$ contain data points reported in previous work (Hansen et al., 2021a; averaged data plotted, $n=6$ ). Lines are for guiding purposes only 
increasing PP reported by the ANOVA is strongly determined by a small minority of the formulations studied; this trend is only observed for 1.25 PPI:sucrose dispersions with 0 and $0.5 \% \mathrm{PP}$, though $1.0 \mathrm{PPI}$ :sucrose dispersions at the same PP concentrations have slightly higher viscosities than the majority of formulations studied. When PP concentration is greater than $0.5 \%$, viscosities of PPI dispersions resemble those of the other formulations (Fig. 3b). The relatively high viscosities measured for PPI dispersions with low PP concentrations $(<1 \%$ PP) may be due to the presence of large insoluble protein particles remaining in dispersions during measurements. As PP increase in the system, there may be more opportunities for protein-PP complexation interactions resulting in aggregates that are smaller than the unhydrated particles and thus reducing system viscosity.

Increased viscosities at $1.5 \% \mathrm{PP}$ are only demonstrated in Fig. 3b for 1.0 and 1.25 SPI:sucrose dispersions, while the majority of formulations showed no meaningful variation in viscosity with increasing PP. The 1.0 and 1.25 SPI:sucrose dispersions, while a minority of the formulations studied, strongly influenced the ANOVA results reported as their viscosities were significantly higher than the other formulations studied. The hydrolyzed SPI was designed to disperse more readily in water with minimal aggregation. Hydrolyzed protein structures have more potential sites available for PP complexation interactions as well, but it appears that a concentration threshold must be met for the SPI in order to start forming an interaction network at high PP concentrations. High PP concentrations likely gave rise to increased intermolecular interactions in the system upon the formation of protein-PP complexes, resulting in increased viscosities and behavioral complexity of the dispersions. Significant increases in viscosity were not observed to occur in formulations with the same SPI:sucrose ratios at lower PP concentrations, indicating that the extreme increase at $1.5 \% \mathrm{PP}$ is likely due to a strong network forming with protein-PP complexation at high protein and PP concentrations. Results reported are generally in agreement with those from earlier experiments, where increasing PP resulted in slight shifts in viscosity for dispersions containing $25 \%$ total solids (Hansen et al. 2021a).

\section{Particle size distribution}

Particle size analysis is useful for evaluating protein-PP interactions in dispersions, as the introduction of $\mathrm{PP}$ changes protein structures, conformation, and electrostatic repulsion, thus affecting the extent of aggregation and resulting particle size distributions of dispersions (Bandyopadhyay et al. 2012; Le Bourvellec \& Renard,
2012; Coupland 2014; Schneider 2016; Hong et al. 2018; Hansen et al. 2021a). According to the ANOVA, protein: sucrose ratio had a significant effect $(p<0.05)$ on the average particle size (volume-weighted mean, $\mathrm{d}_{4,3}$ ) of dispersions. Tukey's HSD tests clarified that increasing protein:sucrose ratios from 0.75 to 1.0 resulted in significantly increased average particle sizes $(p<0.05)$, but the slight increase observed from 1.0 to 1.25 protein:sucrose was not significant $(p>0.05)$. Despite the ANOVA reporting some apparently significant changes in particle size with changing protein:sucrose ratios, plotting the data in Fig. 4a indicated that the shifts were small. These observations are generally in agreement with results from earlier experiments, where WPI:sucrose ratio did not strongly impact the average particle sizes of dispersions (Hansen et al. 2021a).

Changing the protein isolate in formulations between WPI, SPI, and PPI had a significant effect $(p<0.05)$ on the average particle sizes of dispersions, according to the ANOVA. Tukey's HSD tests provided further detail, reporting that WPI dispersions had the smallest average particle sizes, PPI dispersions had the largest, and the average particle sizes of dispersions containing each protein isolate were significantly different from each other. The differences between the average particle sizes of SPI and WPI dispersions are best demonstrated in Fig. 4b, where SPI formulations containing higher PP concentrations $(>0.5 \%)$ are shown to have slightly larger average particle sizes. These findings mirror the trends observed for WHC and viscosity measurements, with WPI having the lowest values and PPI having the highest, likely influenced by differences in the average MW of the isolates and the potential for protein-protein interactions.

While earlier work reported normal distributions for WPI dispersions (Hansen et al. 2021a), the particle size distributions for SPI and PPI dispersions were observed to have different shapes with tails and shoulders to the left and right of the main peaks, as demonstrated in Fig. 5. These differences in distribution shapes may be indicative of the presence of unhydrated particles and protein-PP conjugates of different sizes in dispersions.

According to the ANOVA, average particle sizes of dispersions were significantly affected by PP concentration $(p<0.05)$; Tukey's HSD tests expanded on this, reporting that particle sizes decreased significantly with the addition of 0.5 and $1 \%$ PP to dispersions, with no further change upon 1.5\% PP addition $(p>0.05)$. While in agreement with the findings from previous work with 25\% total solids WPI dispersions (Hansen et al. 2021a), these results appear to be strongly influenced by the data for PPI formulations specifically. Though the results reported by the ANOVA may be observed for PPI dispersions in Fig. 4b, trends observed for WPI and SPI formulations were different; SPI dispersions showed 

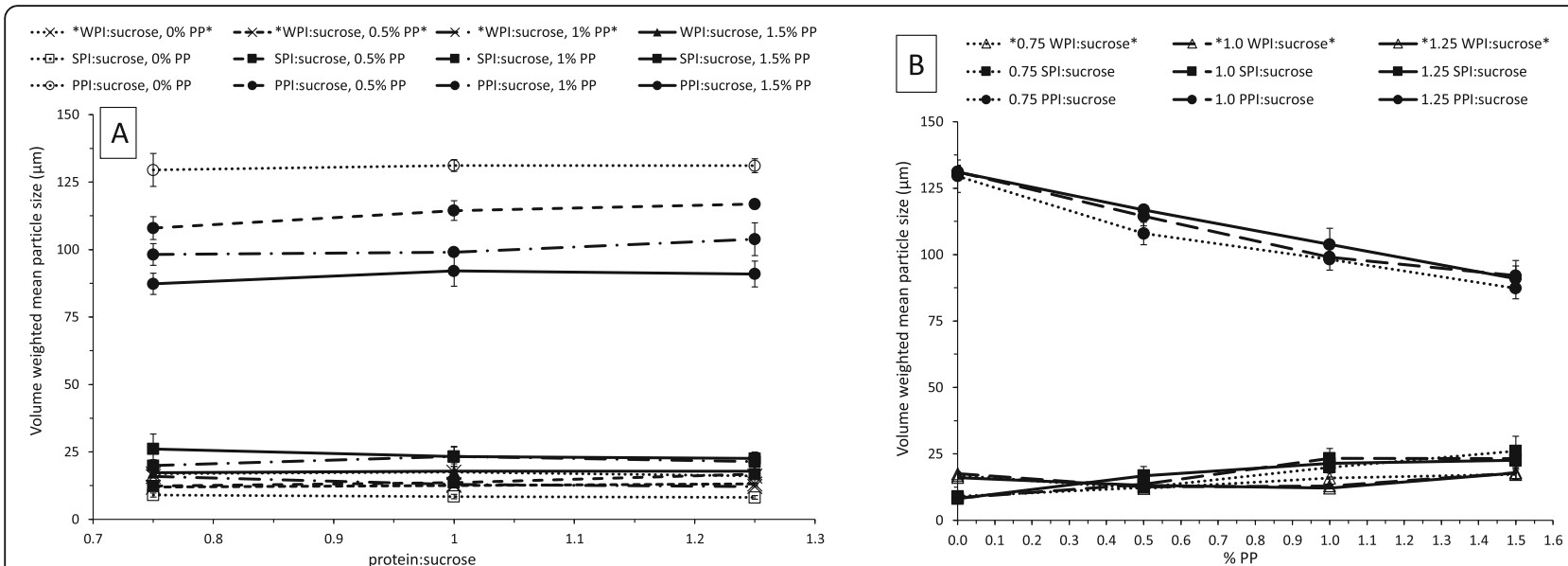

Fig. 4 Effect of protein:sucrose ratio (A) and PP content (\%) (B) on the average particle size $(\mu \mathrm{m})$ of dispersions at $25^{\circ} \mathrm{C}$; (averaged data plotted, $n=9$ ). Legend entries marked * contain data points reported in previous work (Hansen et al., 2021a; averaged data plotted, $n=6$ ). Lines are for guiding purposes only

slightly increasing particle sizes with increasing PP, while WPI dispersions generally showed no meaningful trends or changes, indicative of less extensive protein-PP interactions. Apparently, PPI underwent the least extent of hydration prior to testing, resulting in the presence of many large aggregates in dispersions upon measurement and observation. Formation of protein-PP aggregates in PPI dispersions, which were smaller than the unhydrated PPI particles, likely caused the average particle sizes of dispersions to go down with increasing PP. Additionally, further hydration may have occurred over time, reducing the sizes of larger unhydrated particles in dispersions.
The slight increasing trends observed for particle sizes in SPI dispersions with increasing PP may be due to the same factors that affected viscosity. The hydrolyzed SPI used in this study had smaller average MW proteins than regular SPI; hence, it dispersed easily with minimal protein aggregation, explaining the small particle sizes observed when PP were absent. The hydrolyzed protein structures have more potential sites available for protein-PP interactions than non-hydrolyzed SPI, which may explain the steady increase in particle sizes detected as PP increased in dispersions. While an opposite trend was observed for changes in particle size by Xue et al.

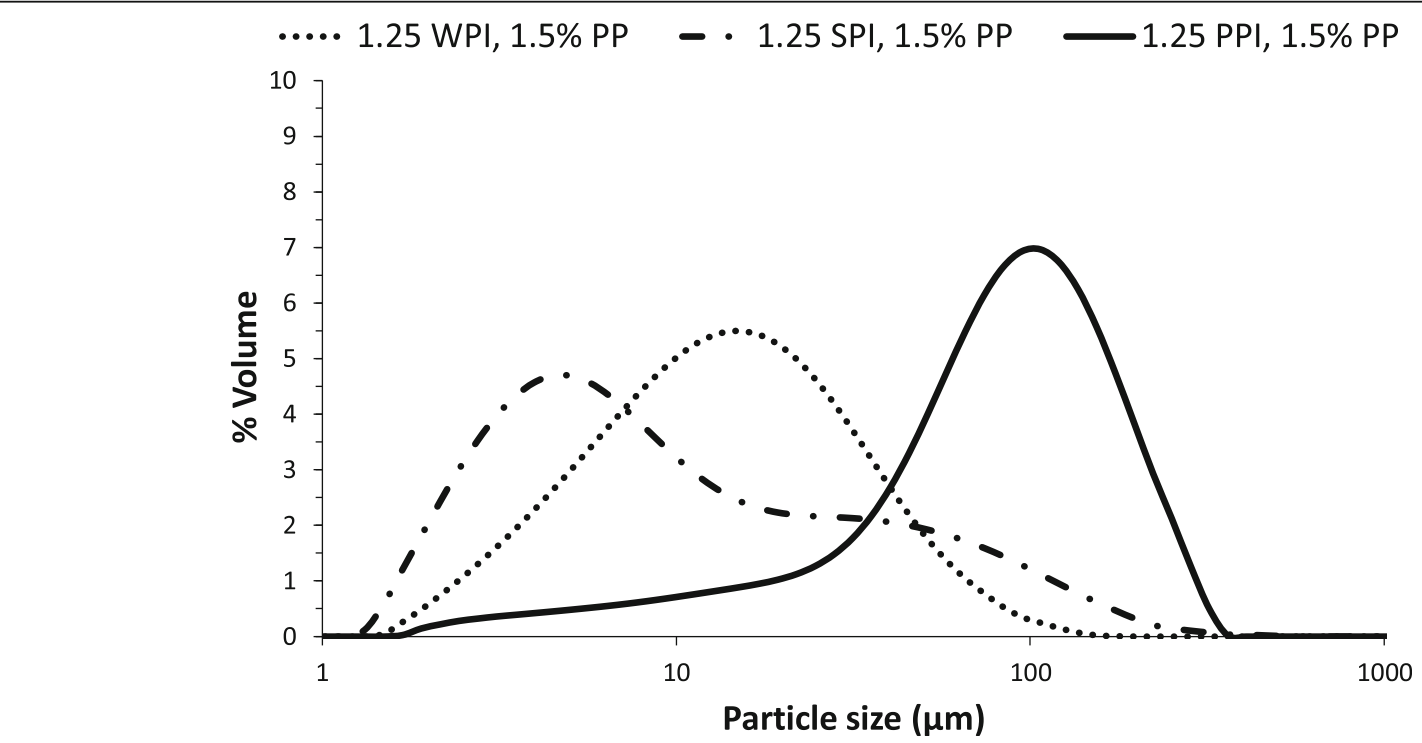

Fig. 5 Particle size distributions of dispersions with 1.25 protein:sucrose ratios and $1.5 \%$ PP contents comprised of WPI, SPI, and PPI at $25^{\circ} \mathrm{C}$; (averaged data plotted, $\mathrm{n}=9$ ) 

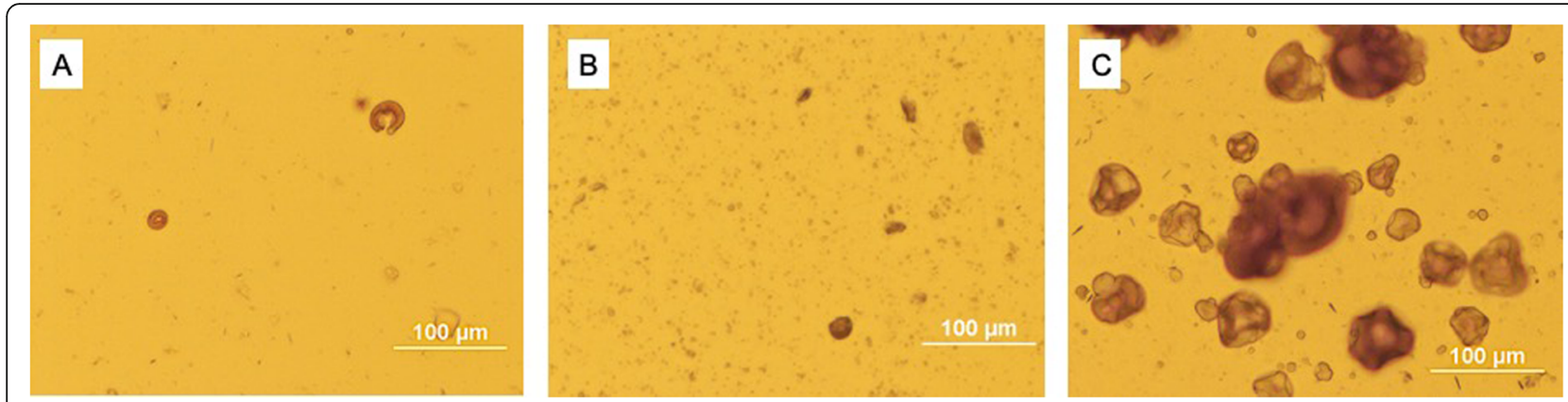

Fig. 6 Optical light microscope images at 200x magnification depicting the microstructures of diluted feed dispersions with a 1.25 protein:sucrose ratio and 1.5\% PP formulated with WPI (A), SPI (B), and PPI (C)

(2020) when studying complexation between SPI and cyanidin-3-galactoside, this may be due to the use of different SPI sources. Thus, increased particle sizes measured in SPI dispersions may be attributed to enhanced protein-PP interactions in the system.

\section{Optical light microscopy}

As with earlier work, particle size data generated by Mastersizer light scattering were supported by microscopy (Hansen et al. 2021a). Although inherent differences exist between the methods making direct comparison of results difficult (Schneider 2016), microscope images depicted Mastersizer data visually, including the variations observed in particle size distributions between dispersions containing WPI, SPI, and PPI (Fig. 5; Fig. 6). Mastersizer data reporting increased average particle sizes with increasing PP in SPI dispersions were reinforced with optical light microscopy (Fig. 7), as were the reduced average particle sizes observed for PPI dispersions with increased PP (Fig. 8).

\section{Centrifuge separation}

Centrifugation resulted in the easy precipitation of pellets out of diluted dispersions, as observed with earlier experiments involving WPI (Hansen et al. 2021a). Centrifuged samples without Aronia PP formed clear supernatants and off-white to tan-colored pellets, while those containing PP formed dark purple pellets (Fig. 10), indicative of protein-PP complexation, as formation of a colored precipitate is a crude method to confirm protein-PP complexation (Van Teeling et al. 1971). Similar to observations from earlier experiments (Hansen et al. 2021a), diluted PP-containing dispersions formed dark purple, transparent supernatant fractions after centrifugation.

Precipitated pellets appeared to be smallest for diluted 1.25 protein-sucrose dispersions with $1.5 \%$ PP containing WPI, and largest for PPI (Fig. 9). Comparing observations from previous experiments (Hansen et al. 2021a), WPI-containing dispersions appeared to form the smallest pellets upon centrifugation (regardless of PP concentration), while SPI dispersions formed slightly larger pellets and PPI formed the largest. Differences in the relative precipitate sizes of the protein isolates may be attributed to the differences in size, where proteins with larger average MW (such as SPI \& PPI) may be more susceptible to precipitating out of solution upon centrifugation than smaller MW proteins like WPI.

Pellet sizes generally appeared to increase slightly with increasing PP in diluted SPI and PPI dispersions (Fig. 10), akin to observations made in previous work for WPI dispersions with increasing PP (Hansen et al. 2021a). Negligible precipitate was formed upon centrifugation of a diluted 1\% Aronia extract solution in

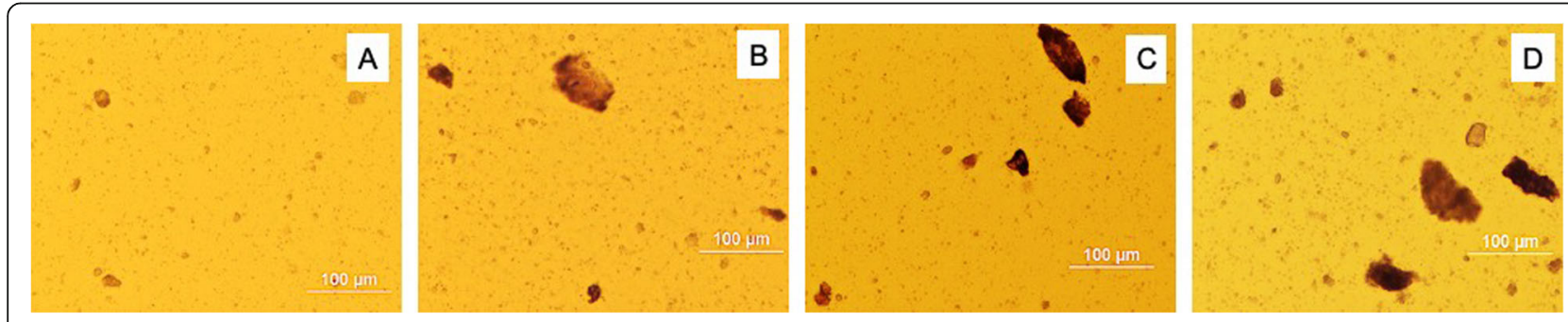

Fig. 7 Optical light microscope images at 200x magnification depicting the microstructures of diluted feed dispersions with 1.0 SPl:sucrose with $0 \%(\mathbf{A}), 0.5 \%(\mathbf{B}), 1 \%(\mathbf{C})$, and $1.5 \%$ PP addition (D) 

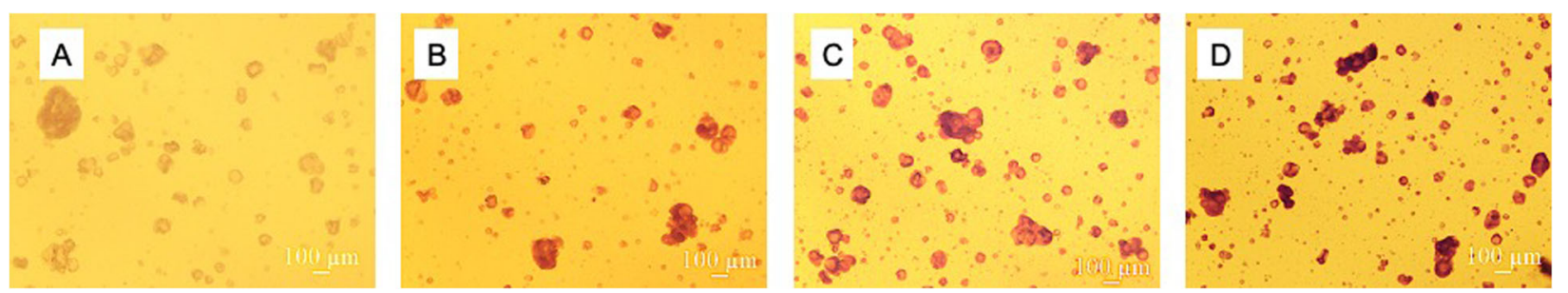

Fig. 8 Optical light microscope images at 40x magnification depicting the microstructures of diluted feed dispersions with 1.0 PPI:sucrose with $0 \%(\mathbf{A}), 0.5 \%(\mathbf{B}), 1 \%(\mathbf{C})$, and $1.5 \%$ PP addition (D)

previous experiments, indicating that the apparent increases in pellet sizes with increasing PP may be a result of the formation of larger, aggregated conjugates precipitating out of solution (Hansen et al. 2021a).

\section{Frozen drop characterization Comparison of diameters}

Dispersions were frozen into drops and diameters were measured to observe the effects of changing protein: sucrose ratios, protein isolate types, and PP concentrations on the sizes of drops formed. According to the ANOVA and corresponding Tukey's HSD tests, changing the protein:sucrose ratios in dispersions did not have a significant impact $(p>0.05)$ on frozen drop diameters (Fig. 11a).

Changing the protein isolate in dispersions between WPI, SPI, and PPI had a slight but statistically significant effect $(p<0.05)$ on the diameters of frozen drops formed, according to the ANOVA. Corresponding Tukey's HSD tests specified that PPI beads had significantly larger diameters than the other isolates $(p<0.05)$, while the smaller diameters of SPI and WPI beads were not significantly different from each other. These findings are depicted in Fig. 11b, where the average frozen diameters of all formulations containing each respective protein isolate are reported. Although surface tension and drop diameters are reported to be directly correlated, our results for measured drop diameters are at odds with this; dispersions with the lowest surface tensions (in this case, PPI formulations) would be expected to have the smallest drop diameters but were actually found to have the largest diameters of the formulations studied. The viscous PPI dispersions (and few SPI formulations) were observed to drip

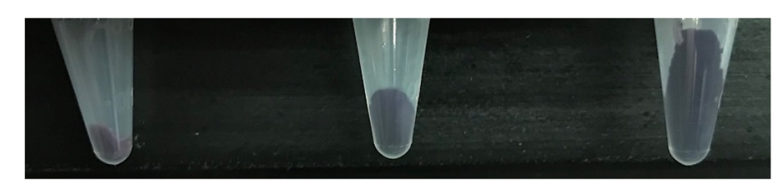

Fig. 9 Image depicting the precipitated fractions (highlighted in boxes) of centrifuged 5x-diluted dispersions with 1.25 protein:sucrose and 1.5\% PP with WPI (Left), SPI (Center), and PPI (Right) irregularly from the tubing tip into nonuniform shapes indicative of more complex fluid behaviors, in contrast to the spherical drops formed by WPI, contributing to the higher variation observed in diameters for beads produced with those isolates.

PP concentration was found to have a significant $(p<$ $0.05)$ impact on frozen drop diameters, according to the ANOVA. In line with previous findings (Hansen et al. 2021a), Tukey's HSD tests reported a significant increase in diameters $(p<0.05)$ when PP was increased from 0 to $0.5 \%$, but the minor increases in diameters observed as PP increased from 0.5 to 1 and $1.5 \%$ were not statistically significant. Drop diameters generally increased with Aronia addition, although some scatter was observed; the increasing trend is most clearly demonstrated for dispersions comprised of PPI:sucrose as PP increased from 0 to $0.5 \%$ in Fig. 11c. These findings are in agreement with the surface tension data, as both surface tension and frozen drop diameters increase with PP addition, in agreement with reports indicating their direct correlation.

Estimated values calculated from flow testing data were compared with the measured diameters of frozen drops (Table 1). While the prediction of drop diameters by calculations was generally successful in previous work focused on WPI dispersions (Hansen et al. 2020, 2021a), the success rates (no significant differences between calculated and measured values; $p<0.05$ ) here were notably

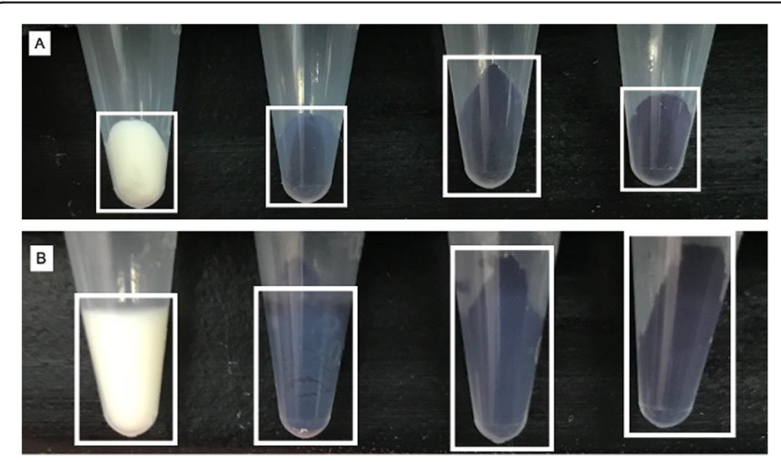

Fig. 10 Images depicting the precipitated fractions (highlighted in boxes) of centrifuged $5 x$-diluted dispersions with 1.25 SPI:sucrose (A) and 5:4 PPI:sucrose (B) and 0\% (Left), 0.5\% (Center, left), 1\% (Center, right), and $1.5 \% \mathrm{PP}$ addition (Right) 


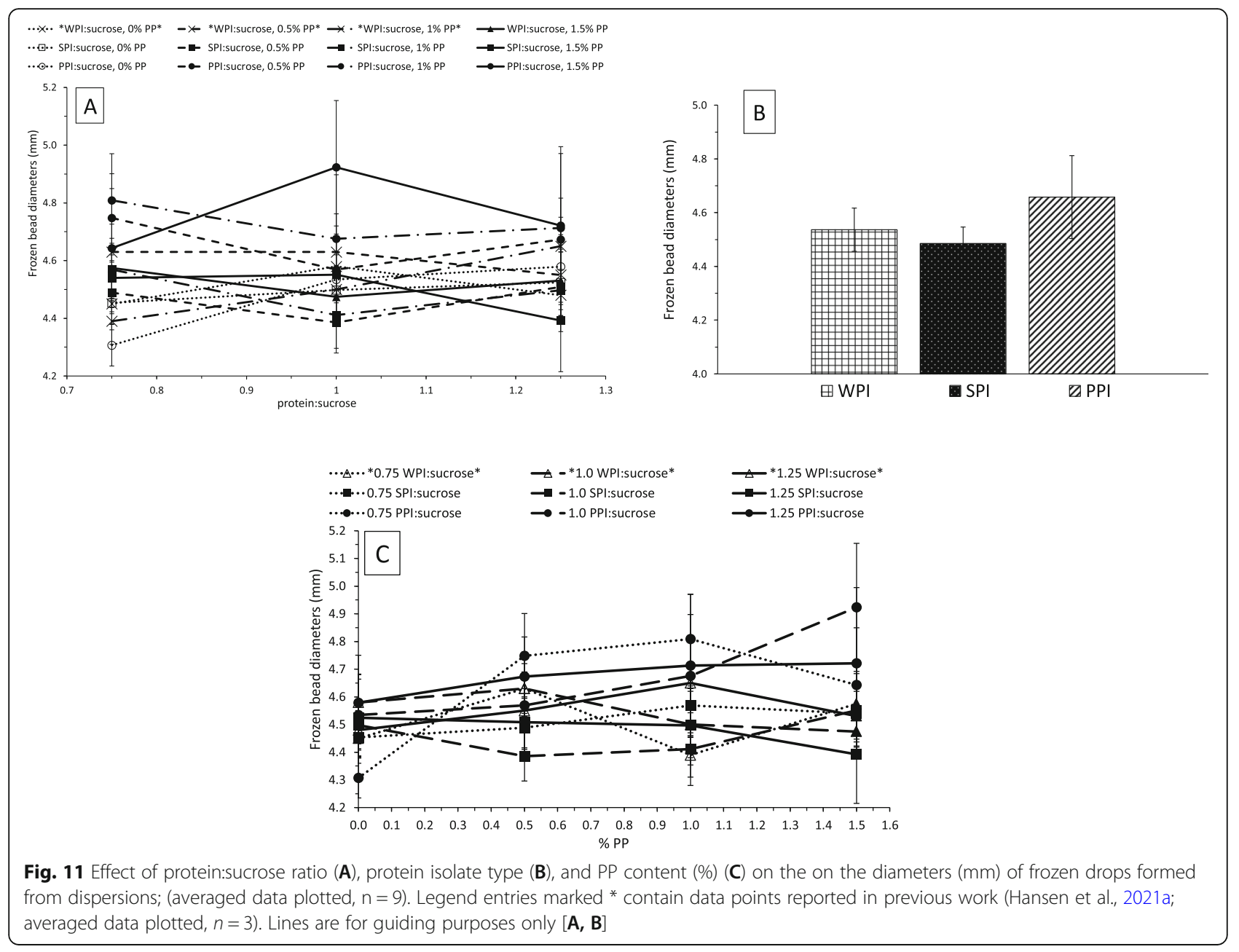

lower. No significant differences were found between the estimated diameters calculated from flow data and the actual measured diameters $75 \%$ of the time for WPI dispersions. SPI dispersions had a success rate of $50 \%$, and PPI dispersions only 33\%. It is possible that the estimated calculations became less accurate in predicting drop diameters because variability increased for the measured drop diameters of SPI and particularly PPI dispersions, when more irregularly shaped, less spherical drops were observed to form.

\section{Conclusions}

To expand on the findings from previous experiments, where liquid dispersions containing WPI, sucrose, and Aronia extract were found to exhibit measurable changes in physicochemical properties attributed to naturally occurring, non-covalent complexation interactions between PP and proteins, this work aimed to investigate whether Aronia PP would interact with plant-based SPI and PPI to a similar extent. The occurrence of non-covalent proteinPP interactions was found to have different effects in SPI and PPI dispersions, nevertheless indicative of more extensive protein-PP interactions than observed in WPI formulations. Increased viscosities and particle sizes were observed for SPI dispersions with increasing PP, while PPI formulations were observed to have reduced viscosities and particle sizes and increased surface tensions. These findings build from previous work to contribute to the body of research describing the physical effects of noncovalent interactions between non-dairy proteins and PP under mild $\mathrm{pH}$ and temperature conditions. Additionally, our results provide empirical insight for applications utilizing concentrated protein-PP mixtures for the development of protective delivery vehicles such as the dry, high protein beads formed by the processes presented in other experiments (Hansen et al. 2020, 2021b). Findings from this study may also inform the formulation of functional foods containing proteins and PP sources like fruit, such as sports beverages, nutritional bars, smoothies, and yogurts, as well as everyday products including pudding and frozen desserts, where specific sensory attributes may be at risk if formulations contain levels of PP and proteins that would be prone to more extensive complexation interactions in mixtures. 


\section{Acknowledgements}

The authors would like to thank the reviewers and Journal Editor for thoughtful reading of the manuscript and constructive comments.

\section{Authors' contributions}

Mackenzie M. Hansen: Conceptualization, Methodology, Validation, Formal analysis, Investigation, Resources, Writing- Original Draft, Writing- Review \& Editing, Visualization, Project administration, Funding acquisition. Richard W. Hartel: Conceptualization, Resources, Writing- Review \& Editing, Visualization, Supervision. Yrjö H. Roos: Conceptualization, Resources, Writing- Review \& Editing, Visualization, Supervision, Funding acquisition. The author(s) read and approved the final manuscript.

\section{Funding}

Funding for this study was provided by the Lauritzson Foundation via the Lauritzson Research Scholarship, through the College of Science, Engineering and Food Science (SEFS) at University College Cork.

\section{Availability of data and materials}

The datasets used and/or analyzed during the current study are available from the corresponding author on reasonable request.

\section{Declarations}

\section{Ethics approval and consent to participate}

Not applicable.

\section{Consent for publication}

Not applicable.

\section{Competing interests}

The authors hereby declare no conflict of interest.

Received: 5 August 2021 Accepted: 7 September 2021

Published online: 01 November 2021

\section{References}

Aschemann-Witzel, J., \& Peschel, A. O. (2019). Consumer perception of plantbased proteins: The value of source transparency for alternative protein ingredients. Food Hydrocolloids, 96, 20-28. https://doi.org/https://doi.org/1 0.1016/j.foodhyd.2019.05.006

Bandyopadhyay, P., Ghosh, A. K., \& Ghosh, C. (2012). Recent developments on polyphenol-protein interactions: Effects on tea and coffee taste, antioxidant properties and the digestive system. Food \& Function, 3(6), 592. https://doi. org/https://doi.org/10.1039/c2fo00006g, 605

Bohin, M. C., Vincken, J.P., van der Hijden, H. T. W. M., \& Gruppen, H. (2012). Efficacy of food proteins as carriers for flavonoids. J Agr Food Chem, 60(16), 4136-4143. https://doi.org/https://doi.org/10.1021/jf205292r

Cao, H., Saroglu, O., Karadag, A., Diaconeasa, Z., Zoccatelli, G., Conte-Junior, C. A. Gonzalez-Aguilar, G. A., Ou, J., Bai, W., Zamarioli, C. M., Freitas, L. A. P., Shpigelman, A., Campelo, P. H., Capanoglu, E., Hii, C. L., Jafari, S. M., Qi, Y., Liao, P., Wang, M., Zou L., Bourke P., Simal-Gandara J. Xiao, J. (2021). Available technologies on improving the stability of polyphenols in food processing. Food Frontiers, fft2.65. https://doi.org/https://doi.org/10.1002/ fft2.65, 2, 2, 109, 139

Cao, Y., \& Xiong, Y. L. (2017). Interaction of Whey Proteins with Phenolic Derivatives Under Neutral and Acidic pH Conditions: Protein-phenolic interaction. Journal of Food Science, 82(2), 409-419. https://doi.org/https://doi. org/10.1111/1750-3841.13607

Chan, E.-S., Lee, B.-B., Ravindra, P., \& Poncelet, D. (2009). Prediction models for shape and size of ca-alginate macrobeads produced through extrusiondripping method. Journal of Colloid and Interface Science, 338(1), 63-72. https://doi.org/https://doi.org/10.1016/j.jcis.2009.05.027

Charlton, A. J., Baxter, N. J., Khan, M. L., Moir, A. J. G., Haslam, E., Davies, A. P., \& Williamson, M. P. (2002). Polyphenol/peptide binding and precipitation. J Agr Food Chem, 50(6), 1593-1601. https://doi.org/https://doi.org/10.1021/ jf010897z

Chung, C., Rojanasasithara, T., Mutilangi, W., \& McClements, D. J. (2015). Enhanced stability of anthocyanin-based color in model beverage systems through whey protein isolate complexation. Food Research International, 76, 761-768. https://doi.org/https://doi.org/10.1016/j.foodres.2015.07.003, Pt 3
Coupland, J. N. (2014). An introduction to the physical chemistry of food, (illustrated ed.). Springer Science + Business Media. New York, NY. https://doi.org/10.1 007/978-1-4939-0761-8.

Demetriades, K., \& McClements, D. J. (1998). Influence of pH and heating on physicochemical properties of whey protein-stabilized emulsions containing a nonionic surfactant. Journal of Agricultural and Food Chemistry, 46(10), 3936-3942. https://doi.org/https://doi.org/10.1021/jf980463c

Fleming, S. E., Sosulski, F. W., Kilara, A., \& Humbert, E. S. (1974). Viscosity and water absorption characteristics of slurries of sunflower and soybean flours, concentrates and isolates. Journal of Food Science, 39(1), 188-192. https:// doi.org/https://doi.org/10.1111/j.1365-2621.1974.tb01019.x

Fuhrmeister, H., \& Meuser, F. (2003). Impact of processing on functional properties of protein products from wrinkled peas. Journal of Food Engineering, 56(2-3), 119-129. https://doi.org/https://doi.org/10.1016/502608774(02)00241-8

González, S. (2020). Dietary bioactive compounds and human health and disease. Nutrients, 12(2), 348. https://doi.org/https://doi.org/10.3390/nu12020348

Hansen, M. M., Hartel, R. W., \& Roos, Y. H. (2021a). Encapsulant-bioactives interactions impact on physico-chemical properties of concentrated dispersions. Journal of Food Engineering, 302, 110586. https://doi.org/https:// doi.org/10.1016/j.ffoodeng.2021.110586

Hansen, M. M., Hartel, R. W., \& Roos, Y. H. (2021b). Formation of dry beads for bioactives encapsulation by freeze granulation [manuscript submitted to journal of food engineering].

Hansen, M. M., Maidannyk, V. A., \& Roos, Y. H. (2020). Thermal gelation and hardening of whey protein beads for subsequent dehydration and encapsulation using vitrifying sugars. Journal of Food Engineering, 279, 109966. https://doi.org/https://doi.org/10.1016/j.jfoodeng.2020.109966

Hartel, R. W., von Elbe, J. H., \& Hofberger, R. (2018). Confectionery science and technology. Springer International Publishing. https://doi.org/https://doi. org/10.1007/978-3-319-61742-8

He, F., Woods, C. E., Litowski, J. R., Roschen, L. A., Gadgil, H. S., Razinkov, V. I., \& Kerwin, B. A. (2011). Effect of sugar molecules on the viscosity of high concentration monoclonal antibody solutions. Pharmaceutical Research, 28(7), 1552-1560. https://doi.org/https://doi.org/10.1007/s11095-011-0388-7

Hong, T., Iwashita, K., \& Shiraki, K. (2018). Viscosity control of protein solution by small solutes: A review. Curr Protein Pept Sc, 19(8), 746-758. https://doi.org/ https://doi.org/10.2174/1389203719666171213114919

Jean, K., Renan, M., Famelart, M.-H., \& Guyomarc'h, F. (2006). Structure and surface properties of the serum heat-induced protein aggregates isolated from heated skim milk. International Dairy Journal, 16(4), 303-315. https://doi.org/ https://doi.org/10.1016/j.idairyj.2005.04.001

Johnson, J. F., Martin, J. R., \& Porter, R. S. (1975). Determination of Viscosity of food systems. In Theory, determination and control of physical properties of food materials, (vol. 1, pp. 25-38). Dordrecht, Springer.

Kanakis, C. D., Hasni, I., Bourassa, P., Tarantilis, P. A., Polissiou, M. G., \& Tajmir-Riahi, H.-A. (2011). Milk $\beta$-lactoglobulin complexes with tea polyphenols. Food Chemistry, 127(3), 1046-1055. https://doi.org/https://doi.org/10.1016/j. foodchem.2011.01.079

Kilara, A., \& Harwalkar, V. R. (1996). Denaturation. In Food proteins: Properties and characterization. Weinheim, Wiley-VCH.

Kitabatake, N., \& Doi, E. (1988). Surface tension and Foamability of protein and surfactant solutions. Journal of Food Science, 53(5), 1542-1569. https://doi. org/https://doi.org/10.1111/j.1365-2621.1988.tb09319.x

Kneifel, W., Paquin, P., Abert, T., \& Richard, J.P. (1991). Water-holding capacity of proteins with special regard to milk proteins and methodological aspects-A review. Journal of Dairy Science, 74(7), 2027-2041. https://doi.org/https://doi. org/10.3168/jds.S0022-0302(91)78373-2

Krstonošić, V. S., Kalić, M. D., Dapčević-Hadnađev, T. R., Lončarević, I. S., \& Hadnađev, M. S. (2020). Physico-chemical characterization of protein stabilized oil-in-water emulsions. Colloids and Surfaces A: Physicochemical and Engineering Aspects, 602, 125045. https://doi.org/https://doi.org/10.101 6/j.colsurfa.2020.125045

Kulmyrzaev, A., Bryant, C., \& McClements, D. J. (2000). Influence of sucrose on the thermal denaturation, gelation, and emulsion stabilization of whey proteins. J Agr Food Chem, 48(5), 1593-1597. https://doi.org/https:/doi.org/10.1021/f9911949

Lam, A. C. Y., Can Karaca, A., Tyler, R. T., \& Nickerson, M. T. (2018). Pea protein isolates: Structure, extraction, and functionality. Food Reviews International, 34(2), 126-147. https://doi.org/https://doi.org/10.1080/87559129.2016.1242135

Le Bourvellec, C., \& Renard, C. M. G. C. (2012). Interactions between polyphenols and macromolecules: Quantification methods and mechanisms. Critical 
Reviews in Food Science and Nutrition, 52(3), 213-248. https://doi.org/ https://doi.org/10.1080/10408398.2010.499808

Lee, B. B., \& Chan, E. S. (2013). Size and shape of calcium alginate beads produced by extrusion dripping. Chemical Engineering and Technology, 36(10), 1627-1642. https://doi.org/https://doi.org/10.1002/ceat.201300230

Li, D., Wang, P., Luo, Y., Zhao, M., \& Chen, F. (2017). Health benefits of anthocyanins and molecular mechanisms: Update from recent decade Critical Reviews in Food Science and Nutrition, 57(8), 1729-1741. https://doi. org/https://doi.org/10.1080/10408398.2015.1030064

$\mathrm{Li}, \mathrm{T}$. S. (2005). Functional and structural properties of molecular soy protein fractions [doctor of philosophy]. Singapore, National University of Singapore.

Li, Y., He, D., Li, B., Lund, M. N., Xing, Y., Wang, Y., Li, F., Cao, X., Liu, Y., Chen, X. Yu, J., Zhu, J., Zhang, M., Wang, Q., Zhang, Y., Li, B., Wang, J., Xing, X., \& Li, L. (2021). Engineering polyphenols with biological functions via polyphenolprotein interactions as additives for functional foods. Trends in Food Science \& Technology, 110, 470-482. https://doi.org/https://doi.org/10.1016/j.tifs.2021. 02.009

Ma, C.-M., \& Zhao, X.-H. (2019). Depicting the non-covalent interaction of whey proteins with Galangin or Genistein using the multi-spectroscopic techniques and molecular docking. Foods, 8(9), 360. https://doi.org/https:// doi.org/10.3390/foods 8090360

Mink, P. J., Scrafford, C. G., Barraj, L. M., Harnack, L., Hong, C.-P., Nettleton, J. A., \& Jacobs, D. R. (2007). Flavonoid intake and cardiovascular disease mortality: A prospective study in postmenopausal women. The American Journal of Clinical Nutrition, 85(3), 895-909. https://doi.org/https://doi.org/10.1093/ajcn/ 85.3 .895

Morr, C. V. (1990). Current status of soy protein functionality in food systems. Journal of the American Oil Chemists' Society, 67(5), 265-271. https://doi.org/ https://doi.org/10.1007/BF02539674

Oancea, A.-M., Aprodu, I., Râpeanu, G., Bahrim, G., \& Stanciuc, N. (2017). The binding mechanism of anthocyanins from sour cherries (Prunus cerasus $L$ ) skins to bovine $\beta$-lactoglobulin: A fluorescence and in silico-based approach. International Journal of Food Properties, 20(sup3), S3096-S3111. https://doi. org/https://doi.org/10.1080/10942912.2017.1343347

Owusu-Ansah, Y. J., \& McCurdy, S. M. (1991). Pea proteins: A review of chemistry, technology of production, and utilization. Food Review International, 7(1), 103-134. https://doi.org/https://doi.org/10.1080/87559129109540903

Ozdal, T., Capanoglu, E., \& Altay, F. (2013). A review on protein-phenolic interactions and associated changes. Food Research International, 51(2), 954970. https://doi.org/https://doi.org/10.1016/j.foodres.2013.02.009

Petruccelli, S., \& Añón, M. C. (1995). Soy protein isolate components and their interactions. Journal of Agricultural and Food Chemistry, 43(7), 1762-1767. https://doi.org/https://doi.org/10.1021/jf00055a004

Quan, T. H., Benjakul, S., Sae-leaw, T., Balange, A. K., \& Maqsood, S. (2019). Proteinpolyphenol conjugates: Antioxidant property, functionalities and their applications. Trends in Food Science and Technology, 91, 507-517. https:// doi.org/https://doi.org/10.1016/j.tifs.2019.07.049

Quinn, J. R., \& Paton, D. (1979). A practical measurement of water hydration capacity of protein materials. Cereal Chemistry, 56(1), 38-40.

Rawel, H. M., Meidtner, K., \& Kroll, J. (2005). Binding of selected phenolic compounds to proteins. J Agr Food Chem, 53(10), 4228-4235. https://doi. org/https://doi.org/10.1021/jf0480290

Resch, J. J., \& Daubert, C. R. (2002). Rheological and physicochemical properties of derivatized whey protein concentrate powders. International Journal of Food Properties, 5(2), 419-434. https://doi.org/https://doi.org/10.1081/JFP-12 0005795

Saluja, A., \& Kalonia, D. S. (2005). Application of ultrasonic shear Rheometer to characterize rheological properties of high protein concentration solutions at microliter volume. Journal of Pharmaceutical Sciences, 94(6), 1161-1168. https://doi.org/https://doi.org/10.1002/jps.20342

Schneider, M. E. (2016). Formation of whey protein-polyphenol aggregates and incorporation into various food structures [PhD food science]. Raleigh, NC, North Carolina State University.

Song, J. (2009). Insight into "insoluble proteins" with pure water. FEBS Letters, 583(6), 953-959. https://doi.org/https://doi.org/10.1016/j.febslet.2009.02.022

Sosulski, F. W., \& McCurdy, Ar. (1987). Functionality of flours, protein fractions and isolates from field peas and faba bean. eJournal of Food Science, 52(4), 1010-1014. https://doi.org/https://doi.org/10.1111/j.1365-2621.1987.tb14263.x

Spencer, C. M., Cai, Y., Martin, R., Gaffney, S. H., Goulding, P. N., Magnolato, D., Lilley, T. H., \& Haslam, E. (1988). Polyphenol complexation—Some thoughts and observations. Phytochemistry, 27(8), 2397-2409. https://doi.org/https:// doi.org/10.1016/0031-9422(88)87004-3

Swanson, B. G. (1990). Pea and lentil protein extraction and functionality. Journal of the American Oil Chemists' Society, 67(5), 276-280. https://doi.org/https:// doi.org/10.1007/BF02539676

Tro, N. J., Fridgen, T. D., \& Shaw, L. (2014). Chemistry: A molecular approach. Toronto, Pearson Canada.

Van Teeling, C. G., Cansfield, P. E., \& Gallop, R. A. (1971). An anthocyanin complex isolated from the syrup of canned blueberries. Journal of Food Science, 36, 1061-1063. https://doi.org/https://doi.org/10.1111/j.1365-2621.1971.tb03346.x, 7

Worley, J. D. (1992). Capillary radius and surface tensions. Using calculations based on Tate's law. Journal of Chemical Education, 69(8), 678.

Xie, L., Lee, S. G., Vance, T. M., Wang, Y., Kim, B., Lee, J.Y., Chun, O. K., \& Bolling, B. W. (2016). Bioavailability of anthocyanins and colonic polyphenol metabolites following consumption of aronia berry extract. Food Chemistry, 211, 860868. https://doi.org/https://doi.org/10.1016/j.foodchem.2016.05.122

Xie, L., Vance, T., Kim, B., Lee, S. G., Caceres, C., Wang, Y., Hubert, P. A., Lee, J.-Y., Chun, O. K., \& Bolling, B. W. (2017). Aronia berry polyphenol consumption reduces plasma total and low-density lipoprotein cholesterol in former smokers without lowering biomarkers of inflammation and oxidative stress: A randomized controlled trial. Nutrition Research, 37, 67-77. https://doi.org/ https://doi.org/10.1016/.nutres.2016.12.007

Xue, F., Li, C., \& Adhikari, B. (2020). Physicochemical properties of soy protein isolates-cyanidin-3-galactoside conjugates produced using free radicals induced by ultrasound. Ultrasonics Sonochemistry, 64, 104990. https://doi. org/https://doi.org/10.1016/j.ultsonch.2020.104990

Zayas, J. F. (1997). Functionality of proteins in food. Springer Berlin Heidelberg, Springer-Verlag. https://doi.org/10.1007/978-3-642-59116-7

Zhao, C., Liu, Y., Lai, S., Cao, H., Guan, Y., San Cheang, W., Liu, B., Zhao, K., Miao, S., Riviere, C., Capanoglu, E., \& Xiao, J. (2019). Effects of domestic cooking process on the chemical and biological properties of dietary phytochemicals. Trends in Food Science \& Technology, 85, 55-66. https://doi.org/https://doi. org/10.1016/j.tifs.2019.01.004

\section{Publisher's Note}

Springer Nature remains neutral with regard to jurisdictional claims in published maps and institutional affiliations.

Ready to submit your research? Choose BMC and benefit from:

- fast, convenient online submission

- thorough peer review by experienced researchers in your field

- rapid publication on acceptance

- support for research data, including large and complex data types

- gold Open Access which fosters wider collaboration and increased citations

- maximum visibility for your research: over $100 \mathrm{M}$ website views per year

At BMC, research is always in progress.

Learn more biomedcentral.com/submissions 